American Journal of Applied Sciences 5(11): 1605-1610, 2008

ISSN 1546-9239

(C) 2008 Science Publications

\title{
On Embeddings of Hamiltonian Paths and Cycles in Extended Fibonacci Cubes
}

\author{
${ }^{1}$ Ioana Zelina, ${ }^{2}$ Grigor Moldovan and ${ }^{1}$ Ioana Tascu \\ ${ }^{1}$ North University of Baia Mare, Victoriei 76, 430122 Baia Mare, Romania \\ ${ }^{2}$ Babes-Bolyai, University of Cluj Napoca, M. Kogalniceanu 1, Cluj Napoca, Romania
}

\begin{abstract}
The interconnection network is an essential component of a distributed system or of a supercomputer based on large-sale parallel processing. Because in distributed systems the communication between processors is based on message exchange, the network topology is of a great importance. The interconnection network can be seen as a graph and the properties of a network can be studied using combinatorics and graph theory. A number of interconnection network topologies have been studied. The Extended Fibonacci Cube, EFC, is a topology which provides good properties for an interconnection network regarding diameter, node degree, recursive decomposition, embeddability and communication algorithms. In this research we present some properties of the Extended Fibonacci Cubes, we define a Gray code for extended Fibonacci cubes and show how a hamiltonian path, a hamiltonian cycle and a 2D mesh can be embedded in an Extended Fibonacci Cube.
\end{abstract}

Key words: Interconnection network, extended Fibonacci cube, embeddings, Gray code, hamiltonian path

\section{INTRODUCTION}

An interconnection network consists of a set of processors, each with a local memory and a set of bidirectional (or unidirectional) links that serve for the exchange of data between processors. Interconnection networks are represented by undirected (or directed if the links are unidirectional) graphs $\mathrm{G}=(\mathrm{V}, \mathrm{E})$ where $\mathrm{V}$ is the set of nodes, each node corresponding to a processor and $\mathrm{E}$ is a set of edges, each edge corresponding to a link. Some of the key features of interest in such an interconnection network are its topological properties as node degree, diameter, connectivity, structure, the embeddability of other topologies and the communication algorithms.

A number of interconnection topologies ${ }^{[1,3,5,9]}$ have been proposed in the literature. A widely studied interconnection topology is the hypercube, or the ncube $H_{n}$. The hypercube has good properties such as symmetry, small diameter and node degree, recursive structure, efficient communication algorithms. A drawback in the case of the hypercube is the number of nodes which is a power of 2 and limits the choice for a network interconnection with a given number of nodes.

$\mathrm{Hsu}^{[5]}$ proposed and studied the properties of a new interconnection topology called Fibonacci cube based on the Fibonacci numbers. The Fibonacci numbers are defined as $f_{0}=0, f_{1}=1, f_{n}=f_{n-1}+f_{n-2}$, for $n>1$. The
Fibonacci cube of order $n$ has $f_{n}$ nodes, $n>1$, where $f_{n}$ is the $n$-th Fibonacci number and the nodes can be labelled with binary strings of length $n-2$ with no consecutive 1's. Two nodes are connected if their labels differ in exactly one position. It is clear that a Fibonacci cube can be seen as resulting from a hypercube after some nodes become faulty. The Fibonacci cube can emulate many of the basic algorithms for the hypercube and there are more Fibonacci numbers in a given interval than powers of 2 .

$\mathrm{Wu}^{[11]}$ generalized the Fibonacci cube topology by defining the series of Extended Fibonacci Cubes, $\left(\mathrm{EFC}_{\mathrm{k}}\right)_{\mathrm{k}>0}$. The Extended Fibonacci Cubes are also defined using the same recursive relation as the Fibonacci numbers, but changing the initial conditions. In this way the number of choices for the number of nodes for an interconnection network increases. The topological properties and embeddings in Extended Fibonacci cubes were studied ${ }^{[6,8,11]}$. In this research we will define a Gray code for extended Fibonacci cubes and using this code we will define a hamiltonian path in an extended Fibonacci cube.

\section{FIBONACCI CUBES AND EXTENDED FIBONACCI CUBES}

The Fibonacci Cube topology is based on the properties of Fibonacci numbers. The Fibonacci

Corresponding Author: Ioana Zelina, Department of Mathematics and Informatics, North University of Baia Mare, Victoriei, No.76, 430122, Baia Mare, 0040- 262-276059 
$\Gamma_{2}$

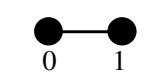

$\Gamma_{3}$

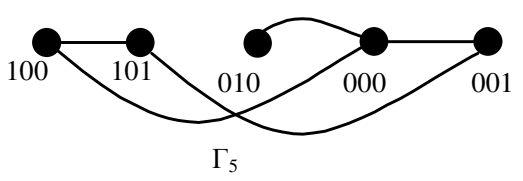

Fig. 1: Fibonacci cubes $\Gamma_{2}, \Gamma_{3}, \Gamma_{4}, \Gamma_{5}$

numbers are defined as $\mathrm{f}_{0}=0, \mathrm{f}_{1}=1, \mathrm{f}_{\mathrm{n}}=\mathrm{f}_{\mathrm{n}-1}+\mathrm{f}_{\mathrm{n}-2}$, for $\mathrm{n}>1$. According to Zeckendorf's lemma any integer number $k, 0 \leq k<f_{n}$ can be written as a sum of Fibonacci numbers as it follows:

$$
\mathrm{k}=\sum_{\mathrm{i}=2}^{\mathrm{n}-1} \mathrm{~b}_{\mathrm{i}} \cdot \mathrm{f}_{\mathrm{i}}, \mathrm{b}_{\mathrm{i}} \in\{0,1\}, \mathrm{b}_{\mathrm{i}} \cdot \mathrm{b}_{\mathrm{i}+1}=0, \mathrm{i}=\overline{1, \mathrm{n}-2}
$$

This means that to every integer number $\mathrm{k}, 0 \leq \mathrm{k}<\mathrm{f}_{\mathrm{n}}$, we can associate a Fibonacci code $k_{F}=\left(b_{n-1} \ldots b_{3} b_{2}\right)_{F}$ according to its representation as a sum of Fibonacci numbers. This code is a binary code which has no two consecutive 1's and is called Fibonacci code. Any binary string with no two consecutive 1's is called Fibonacci string.

The Fibonacci cube can be defined as follows:

Definition 1: The Fibonacci cube of order $n>1$, denoted by $\Gamma_{n}$, is defined as $\Gamma_{n}=\left(V_{n}, E_{n}\right)$ where the set of nodes is $V_{n}=\left\{0,1, \ldots, f_{n}-1\right\}$ and the set of edges $E_{n}$ is $E_{n}=\left\{(i, j) \mid H\left(i_{F}, j_{F}\right)=1, i, j \in V_{n}\right\}$, where $H\left(i_{F}, j_{F}\right)$ is the Hamming distance between the Fibonacci codes of nodes $\mathrm{i}$ and $\mathrm{j}$.

The Fibonacci cube of order $n$ has $f_{n}$ nodes and there is an edge between two nodes if their Fibonacci codes differ exactly in one position. The Fibonacci cubes of order 2, 3, 4, 5 are represented in Fig. 1.

A recursive definition for the Fibonacci cubes has been given $^{[5]}$ as follows:

Definition 2: The Fibonacci cube $\Gamma_{n}=\left(V_{n}, E_{n}\right)$ of order $\mathrm{n}, \mathrm{n}>1$, is defined recursively as $\mathrm{V}_{\mathrm{n}}=0\left\|\mathrm{~V}_{\mathrm{n}-1} \cup 10\right\| \mathrm{V}_{\mathrm{n}-2}$, where $V_{n-1}$ and $V_{n-2}$ are the set of nodes of the order $n-1$ respectively $\mathrm{n}-2$ Fibonacci cubes and $\|$ denotes the concatenation of strings and there is an edge between two nodes if their binary representations differ exactly in one position. The initial conditions are $\Gamma_{2}=(\{\lambda\}, \varnothing)$ and $\Gamma_{3}=(\{0,1\},\{(0,1)\})$.

A Fibonacci cube of order $n, \Gamma_{n}$, has $f_{n}$ nodes and can be recursively decomposed in two Fibonacci cubes of order $\mathrm{n}-1$ and $\mathrm{n}-2$. The two $\Gamma_{\mathrm{n}-1}$ and $\Gamma_{\mathrm{n}-2}$ are connected by $\mathrm{f}_{\mathrm{n}-1}$ edges. The Fibonacci cube has good properties: the nodes degree is between $n / 8$ and $n-2$, the diameter is $\mathrm{n}-2$, the node and edge connectivity are between $n / 8$ and $(n-2) / 3$ respectively, basic topologies such as arrays, rings, meshes, hypercubes can be embedded in Fibonacci cubes. But just the Fibonacci cubes with an even number of nodes, greater than 2 are hamiltonian.

$\mathrm{Wu}^{[11]}$ introduced a series of Extended Fibonacci cubes $\left(\mathrm{EFC}_{\mathrm{k}}\right)_{\mathrm{k}>1}$, using a recursive definition. All the cubes in the series have an even number of nodes and they are hamiltonian.

Definition 3: The series of Extended Fibonacci cubes, $\left(\mathrm{EFC}_{\mathrm{k}}\right)_{\mathrm{k}>1}$, is defined as $\mathrm{EFC}_{\mathrm{k}}(\mathrm{n})=\left(\mathrm{V}_{\mathrm{k}}(\mathrm{n}), \mathrm{E}_{\mathrm{k}}(\mathrm{n})\right)$, $\mathrm{n}>\mathrm{k}+1$, where $\mathrm{V}_{\mathrm{k}}(\mathrm{n})=0\left\|\mathrm{~V}_{\mathrm{k}}(\mathrm{n}-1) \cup 10\right\| \mathrm{V}_{\mathrm{k}}(\mathrm{n}-2), \mathrm{n}>\mathrm{k}+3$ and two nodes are connected by an edge in $\mathrm{E}_{\mathrm{k}}(\mathrm{n})$ if their binary representation differ in exactly one position. The initial conditions are $\mathrm{V}_{\mathrm{k}}(\mathrm{k}+2)=\{0,1\}^{\mathrm{k}}, \mathrm{V}_{\mathrm{k}}(\mathrm{k}+3)=\{0,1\}^{\mathrm{k}+1}$ and $\{0,1\}^{\mathrm{k}}$ denotes the set of binary strings of length $\mathrm{k}$.

From this definition we can see that an extended Fibonacci cube $\mathrm{EFC}_{\mathrm{k}}(\mathrm{n})$ can be decomposed in two extended Fibonacci cubes $\operatorname{EFC}_{k}(n-1)$ and $\operatorname{EFC}_{k}(n-2)$ and each node in $\mathrm{EFC}_{\mathrm{k}}(\mathrm{n}-2)$ is connected to a node in $\mathrm{EFC}_{\mathrm{k}}(\mathrm{n}-1)$.

The nodes of an $\operatorname{EFC}_{k}(n)$ are labelled with binary strings of length $n-2$, where the first n-k-2 bits represent a Fibonacci code and the last $\mathrm{k}$ represent any binary code. The number of nodes in $\operatorname{EFC}_{k}(n)$ is $2^{k} f_{n-k}$, where $\mathrm{f}_{\mathrm{n}-\mathrm{k}}$ is the (n-k)-th Fibonacci number, $\mathrm{n}>\mathrm{k}+1$. We can consider the Fibonacci cube $\Gamma_{\mathrm{n}}$ as an extended Fibonacci cube $\mathrm{EFC}_{0}(\mathrm{n})$. The extended Fibonacci cubes $\mathrm{EFC}_{1}(3), \mathrm{EFC}_{1}(4), \mathrm{EFC}_{1}(5)$ and $\mathrm{EFC}_{2}(6)$ are given in Fig. 2.

Some important properties ${ }^{[6,8,11]}$ of extended Fibonacci cubes are:

- The diameter of $\operatorname{EFC}_{\mathrm{k}}(\mathrm{n})$ is $\mathrm{n}-2$

- The degree $g(u)$ of a node $u$ in $\operatorname{EFC}_{k}(n)$ is $\left\lceil\frac{\mathrm{n}-(\mathrm{k}-1)}{3}\right\rceil+(\mathrm{k}-1) \leq \mathrm{g}(\mathrm{u}) \leq \mathrm{n}-2$

- $\quad \mathrm{EFC}_{\mathrm{n}-2}(\mathrm{n})=\mathrm{H}_{\mathrm{n}-2}$ for $\mathrm{n}>2$

- $\Gamma_{\mathrm{n}=} \mathrm{EFC}_{0}(\mathrm{n}) \subset \mathrm{EFC}_{1}(\mathrm{n}) \subset \ldots \subset \mathrm{EFC}_{\mathrm{n}-2}(\mathrm{n})=\mathrm{H}_{\mathrm{n}-2}$

Scarano ${ }^{[8]}$ showed that excepting the initial values, the number of nodes in $\mathrm{EFC}_{\mathrm{k}}(\mathrm{n})$ are distinct for different values of $k$ and $n, k \geq 0, n \geq k+2$. This means that using extended Fibonacci cubes, the possibility of constructing a hypercube-like topology increases. For example, if we want to construct a cube with the 

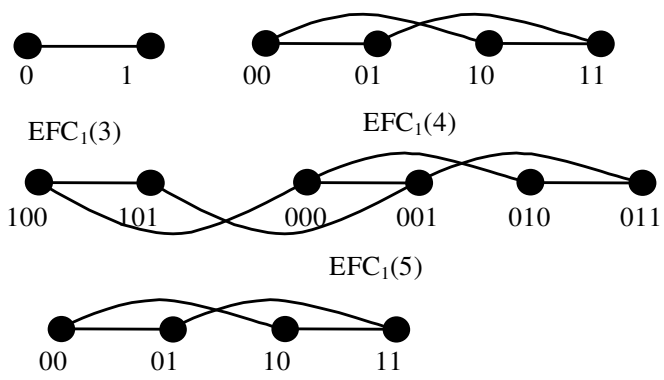

$\mathrm{EFC}_{2}(4)$
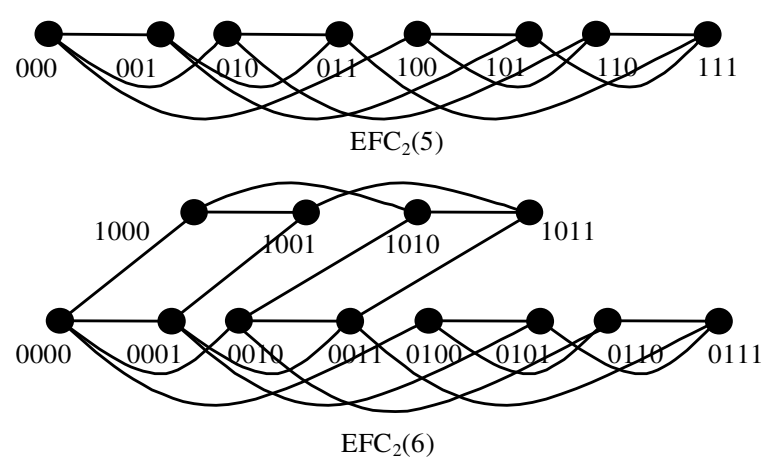

Fig. 2: Extended Fibonacci cubes $\mathrm{EFC}_{1}(3), \mathrm{EFC}_{1}(4)$, $\mathrm{EFC}_{1}(5), \mathrm{EFC}_{1}(6), \mathrm{EF}_{2}(4), \mathrm{EFC}_{2}(5), \mathrm{EFC}_{2}(6)$

number of nodes between 10 and 50 we can choose only two hypercubes, $\mathrm{H}_{4}$ and $\mathrm{H}_{5}$ with 16 respectively 32 nodes, but there are 11 choices of extended Fibonacci cubes: $\mathrm{EFC}_{1}(6), \mathrm{EFC}_{2}(6), \mathrm{EFC}_{0}(7), \mathrm{EFC}_{2}(7), \mathrm{EFC}_{0}(8)$, $\mathrm{EFC}_{3}(7), \mathrm{EFC}_{1}(8), \mathrm{EFC}_{0}(9), \mathrm{EFC}_{3}(8), \mathrm{EFC}_{1}(10)$ and $\mathrm{EFC}_{4}(8)$ with the number of nodes $10,12,13,20,21$, $24,26,34,40,42,48$ respectively.

An embedding of a guest graph $\mathrm{G}=\left(\mathrm{V}_{\mathrm{G}}, \mathrm{E}_{\mathrm{G}}\right)$ in a host graph $\mathrm{H}=\left(\mathrm{V}_{\mathrm{H}}, \mathrm{E}_{\mathrm{H}}\right)$ is defined as a mapping of the nodes $\mathrm{V}_{\mathrm{G}}$ in $\mathrm{V}_{\mathrm{H}}$. The dilation of an edge of $\mathrm{G}$ is defined as the length of the path onto which the edge in $G$ is mapped in $\mathrm{H}$. The dilation of an embedding is the maximum dilation of its edges. The congestion of an edge is the number of paths in $\mathrm{H}$ that contain that edge and the congestion of the embedding is the maximum congestion of its edges.

The load of an embedding is the maximum number of processors in $\mathrm{G}$ assigned to any processor in $\mathrm{H}$. We are interested in this research only in one-to-one mappings, so the load of any embedding is one. The dilation and congestion of an embedding are measures of communication delay and congestion over a link. An ideal embedding has low dilation and congestion.

$\mathrm{Wu}^{[11]}$ gave some embeddings of hypercubes and trees in $\mathrm{EFC}_{\mathrm{k}}$.

A complete binary tree of height $n, B(n)$, has $2^{n+1}-1$ nodes. A n-level double-rooted complete binary tree
$\mathrm{DRCB}(\mathrm{n})$ is obtained from a complete binary tree $\mathrm{B}(\mathrm{n})$ replacing the root by a path of length two and has $2^{\mathrm{n}+1}$ nodes.

The following embeddings are described by $\mathrm{Wu}^{[11]}$ :

- $\mathrm{EFC}_{\mathrm{k}}(\mathrm{n})$ is a subgraph of $\mathrm{H}_{\mathrm{n}-2}$

- $\mathrm{H}_{\mathrm{k}}=\mathrm{EFC}_{\mathrm{k}}(\mathrm{k}+2), \mathrm{H}_{\mathrm{k}+1}=\mathrm{EFC}_{\mathrm{k}}(\mathrm{k}+3)$ and $\mathrm{H}_{\mathrm{n}}$ is a proper subgraph of $\mathrm{EFC}_{k}(2 n-k+1)$ for $n>k+2$ that means a hypercube $H_{n}$ can be embedded in any $\mathrm{EFC}_{\mathrm{k}}(2 \mathrm{n}-\mathrm{k}+1)$ with dilation and congestion 1 , $\mathrm{n}>\mathrm{k}+2$

- A complete binary tree of height $n, B(n)$ can be embedded in $\mathrm{EFC}_{1}(2 \mathrm{n}+2)$ with dilation and congestion two

- A complete binary tree of height $n, B(n)$ can be embedded in $\mathrm{EFC}_{1}(2 \mathrm{n}+6)$ with dilation and congestion one

- A double rooted complete binary tree $\operatorname{DRCB}(2 n+4)$ can be embedded in $\mathrm{EFC}_{1}(3 n+9)$ with dilation and congestion two, $n \geq 0$

- $\operatorname{DRCB}(2 n+1)$ can be embedded in $\mathrm{FC}(3 n+5)$ with dilation and congestion two, $\mathrm{n} \geq 0$

\section{RESULTS AND DISCUSSION}

Next we will show that in an $\mathrm{EFC}_{\mathrm{k}}(\mathrm{n})$ we can define a hamiltonian path. This path will be constructed using a Gray code for extended Fibonacci cubes. This code will be defined using the Gray codes for Fibonacci strings and for binary strings.

The Gray code for binary strings is recursively defined as $\mathrm{C}_{1}=\{0,1\}, \mathrm{C}_{\mathrm{k}}=\left\{0 \mathrm{C}_{\mathrm{k}-1}, 1 \mathrm{C}_{\mathrm{k}-1}^{\prime}\right\}, \mathrm{k}>1$ and the Gray code for Fibonacci strings is recursively defined as $G_{3}=\{0,1\}, G_{4}=\{01,00,10\}, G_{n+2}=\left\{0 G_{n+1}^{\prime}, 10 G_{n}^{\prime}\right\}$, $\mathrm{n}>2$, where $\mathrm{C}^{\prime}{ }_{\mathrm{k}}, \mathrm{G}^{\prime}{ }_{\mathrm{k}}$ denotes the reverse sequence of the elements in $C^{\prime}{ }_{k}$ respectively $G^{\prime}{ }_{k}$. The Gray code $G_{n+2}$ contains all the Fibonacci codes of length $\mathrm{n}$ and the Gray code $\mathrm{C}_{\mathrm{k}}$ contains all the binary strings of length $\mathrm{k}$.

Let $\mathrm{C}_{\mathrm{k}}=\left\{\mathrm{w}_{1}, \mathrm{w}_{2}, \ldots, \mathrm{w}_{\mathrm{p}}\right\}, \mathrm{p}=2^{\mathrm{k}}$, be the Gray code for binary strings of length $\mathrm{k}, \mathrm{H}\left(\mathrm{w}_{\mathrm{i}}, \mathrm{w}_{\mathrm{i}+1}\right)=1,1 \leq \mathrm{i} \leq \mathrm{p}-1$ and $\mathrm{G}_{\mathrm{n}-\mathrm{k}}=\left\{\mathrm{v}_{1}, \mathrm{v}_{2}, \ldots, \mathrm{v}_{\mathrm{q}}\right\}, \mathrm{q}=\mathrm{f}_{\mathrm{n}-\mathrm{k}}$, the Gray code for Fibonacci strings of length $n-k-2, H\left(v_{i}, v_{i+1}\right)=1$, where $1 \leq \mathrm{i} \leq \mathrm{q}-1$.

Using these Gray codes we give the following definition for a sequence of nodes in an $\mathrm{EFC}_{k}(\mathrm{n})$ which we will show to be a Gray code for $\mathrm{EFC}_{k}(\mathrm{n})$.

Definition 4: We call an extended Fibonacci sequence the sequence defined as:

$\mathrm{EG}_{\mathrm{k}}(\mathrm{n})=\left\{\mathrm{v}_{1} \mathrm{C}_{\mathrm{k}}, \mathrm{v}_{2} \mathrm{C}^{\prime}{ }_{\mathrm{k}}, \mathrm{v}_{3} \mathrm{C}_{\mathrm{k}}, \ldots, \mathrm{v}_{\mathrm{q}} \mathrm{C}^{\prime \prime}{ }_{\mathrm{k}}\right\}, \mathrm{q}=\mathrm{f}_{\mathrm{n}-\mathrm{k}}$ where, $v_{i} C_{k}=\left\{v_{i} w_{1}, v_{i} w_{2}, \ldots, v_{i} w_{p}\right\}, p=2^{k}$ and $v_{i} C^{\prime}{ }_{k}=$ $=\left\{\mathrm{v}_{\mathrm{i}} \mathrm{w}_{\mathrm{p}}, \mathrm{v}_{\mathrm{i}} \mathrm{w}_{\mathrm{p}-1}, \ldots, \mathrm{v}_{\mathrm{i}} \mathrm{w}_{1}\right\}$ represent the sequences of 
strings obtained from concatenation of string $\mathrm{v}_{\mathrm{i}}$ with all the strings $\mathrm{w}_{\mathrm{j}}$ in $\mathrm{C}_{\mathrm{k}}$, respectively $\mathrm{C}_{\mathrm{k}}{ }, \mathrm{i} \in\{1, \ldots, \mathrm{q}\}$ and $\mathrm{C}{ }_{\mathrm{k}}=\mathrm{C}_{\mathrm{k}}$ if q is odd and $\mathrm{C}{ }_{\mathrm{k}}=\mathrm{C}{ }_{\mathrm{k}}$ if q is even.

The extended Fibonacci sequence defined has $\mathrm{pq}=\mathrm{f}_{\mathrm{n}-\mathrm{k}} \cdot 2^{\mathrm{k}}$ elements and the strings in $\mathrm{EG}_{\mathrm{k}}(\mathrm{n})$ are exactly the nodes of $\mathrm{EFC}_{\mathrm{k}}(\mathrm{n})$.

We will prove that the extended Fibonacci sequence defined is a Gray code.

Lemma 5: The extended Fibonacci sequence is a Gray code.

Proof: We need to prove that the Hamming distance between two consecutive binary strings in $\mathrm{EG}_{\mathrm{k}}(\mathrm{n})$ is 1 . Let $\mathrm{x}$ and $\mathrm{y}$ be two consecutive binary strings in $\mathrm{EG}_{\mathrm{k}}(\mathrm{n})$. If $\mathrm{x}$ and $\mathrm{y}$ are in the same $\mathrm{v}_{\mathrm{i}} \mathrm{C}_{\mathrm{k}}$ or $\mathrm{v}_{\mathrm{i}} \mathrm{C}^{\prime}{ }_{\mathrm{k}}$ subsequence, we have that the Hamming distance between $x$ and $y$ is $H(x, y)=H\left(v_{i} w_{j}, v_{i} w_{j+1}\right)=H\left(w_{j}\right.$, $\left.\mathrm{w}_{\mathrm{j}+1}\right)=1$ for $\mathrm{j}=1, \mathrm{p}-1$ or $\mathrm{H}(\mathrm{x}, \mathrm{y})=\mathrm{H}\left(\mathrm{v}_{\mathrm{i}} \mathrm{w}_{\mathrm{j}}\right.$, $\left.\mathrm{v}_{\mathrm{i}} \mathrm{w}_{\mathrm{j}-1}\right)=\mathrm{H}\left(\mathrm{w}_{\mathrm{j}}, \mathrm{w}_{\mathrm{j}-1}\right)=1$ for $\mathrm{j}=1$,p. If $\mathrm{x}$ is the last string in $\mathrm{v}_{\mathrm{i}} \mathrm{C}_{\mathrm{k}}$ and $\mathrm{y}$ the first string in $\mathrm{v}_{\mathrm{i}+1} \mathrm{C}_{\mathrm{k}}$ or $\mathrm{x}$ is the last string in $\mathrm{v}_{\mathrm{i}} \mathrm{C}_{\mathrm{k}}{ }_{\mathrm{k}}$ and $\mathrm{y}$ the first in $\mathrm{v}_{\mathrm{i}+1} \mathrm{C}_{\mathrm{k}}$ then $\mathrm{H}(\mathrm{x}, \mathrm{y})=\mathrm{H}\left(\mathrm{v}_{\mathrm{i}} \mathrm{w}_{\mathrm{p}}, \mathrm{v}_{\mathrm{i}+1} \mathrm{w}_{\mathrm{p}}\right)=\mathrm{H}\left(\mathrm{v}_{\mathrm{i}}, \mathrm{v}_{\mathrm{i}+1}\right)=1,1 \leq \mathrm{i} \leq \mathrm{q}-1$ or $\mathrm{H}(\mathrm{x}, \mathrm{y})=\mathrm{H}\left(\mathrm{v}_{\mathrm{i}} \mathrm{w}_{1}, \mathrm{v}_{\mathrm{i}+1} \mathrm{w}_{1}\right)=\mathrm{H}\left(\mathrm{v}_{\mathrm{i}}, \mathrm{v}_{\mathrm{i}+1}\right)=1,1 \leq \mathrm{i} \leq \mathrm{q}-1$. The Hamming distance between two consecutive strings in $\mathrm{EG}_{\mathrm{k}}(\mathrm{n})$ is 1 and $\mathrm{EG}_{\mathrm{k}}(\mathrm{n})$ is a Gray code.

We can give now the following theorem:

Theorem 6: Any extended Fibonacci cube $\mathrm{EFC}_{\mathrm{k}}(\mathrm{n})$ contains a hamiltonian path.

Proof: The extended Fibonacci sequence $\mathrm{EG}_{\mathrm{k}}(\mathrm{n})$ contains all the nodes in $\operatorname{EFC}_{k}(n)$. The Hamming distance between two consecutive elements in $\mathrm{EG}_{\mathrm{k}}(\mathrm{n})$ is one, so two consecutive elements in $\mathrm{EG}_{\mathrm{k}}(\mathrm{n})$ are neighbours in the extended Fibonacci cube $\operatorname{EFC}_{k}(n)$. This means that the sequence $\mathrm{EG}_{\mathrm{k}}(\mathrm{n})$ defines a hamiltonian path in $\mathrm{EFC}_{\mathrm{k}}(\mathrm{n})$.

For example, for $\mathrm{EFC}_{2}(6)$ the Gray code $\mathrm{C}_{2}$ is $\mathrm{C}_{2}=$ $\{00,01,11,10\}$ and the Gray code for Fibonacci strings $\mathrm{G}_{4}$ is $\mathrm{G}_{4}=\{01,00,10\}$. The extended Fibonacci sequence is $\mathrm{EG}_{2}(6)=\left\{01 \mathrm{C}_{2}, 00 \mathrm{C}_{2}, 10 \mathrm{C}_{2}\right\}=\{0100$, 0101, 0111, 0110, 0010, 0011, 0001, 0000, 1000, 1001, $1011,1010\}$ and defines a hamiltonian path in $\mathrm{EFC}_{2}(6)$.

$\mathrm{Wu}^{[11]}$ showed how a hamiltonian cycle can be embedded in $\mathrm{EFC}_{1}$. We will show next how a hamiltonian cycle can be embedded in any, $\mathrm{EFC}_{\mathrm{k}}, \mathrm{k} \geq 1$ using the extended Fibonacci sequence defined in 4. We give first two lemmas.
Lemma 7: In any Gray code $C_{k}=\left\{w_{1}, w_{2}, \ldots, w_{p-1}, w_{p}\right\}$, $\mathrm{k}>1, \mathrm{p}=2^{\mathrm{k}}, \mathrm{w}_{1}$ and $\mathrm{w}_{\mathrm{p}}$ have 0 as their last digit and $\mathrm{w}_{2}$ and $\mathrm{w}_{\mathrm{p}-1}$ have 1 as their last digit.

Of course, the same property holds for $\mathrm{C}_{\mathrm{k}}$.

The proof of this lemma follows immediately using mathematical induction.

Let $C_{k}$ be the Gray code of order $k, C_{k}=\left\{w_{1}, w_{2}\right.$, $\left.\ldots, \mathrm{w}_{\mathrm{p}}\right\}, \mathrm{p}=2^{\mathrm{k}}$ and $\mathrm{C}_{\mathrm{k}}^{0}$ and $\mathrm{C}_{\mathrm{k}}{ }^{1}$ the subsequences of $\mathrm{C}_{\mathrm{k}}$ that contains only the strings with 0 , respectively 1 on their last position (the two subsequences have the same number of elements), $\mathrm{C}_{\mathrm{k}}{ }^{0}=\left\{\mathrm{w}_{\mathrm{i} 1} 0, \mathrm{w}_{\mathrm{i} 2} 0, \ldots, \mathrm{w}_{\mathrm{im}} 0\right\}$, $\mathrm{C}_{\mathrm{k}}{ }^{1}=\left\{\mathrm{w}_{\mathrm{i} 1} 1, \mathrm{w}_{\mathrm{i} 2} 1, \ldots, \mathrm{w}_{\mathrm{im}} 1\right\}$, with $\mathrm{i} 1<\mathrm{i} 2<\ldots<\mathrm{im}$ and $\mathrm{j} 1<\mathrm{j} 2<\ldots<\mathrm{jm}$, where $\mathrm{m}=2^{\mathrm{k}-1}$.

Lemma 8: Any two consecutive elements in $\mathrm{C}_{\mathrm{k}}{ }^{0}$ respectively in $\mathrm{C}_{\mathrm{k}}{ }^{1}, \mathrm{k}>2$, have the Hamming distance one.

Proof: We use the induction to prove this lemma. For $\mathrm{k}=3, \mathrm{C}_{3}=\{00,01,11,10\}, \mathrm{C}_{3}{ }^{0}=\{00,10\}$, $\mathrm{C}_{3}{ }^{1}=\{00,10\}$ and the Hamming distances are 1 .

For $\mathrm{k}=4, \mathrm{C}_{4}=\{000,001,011,010,110,111,101$, $100\}, C_{4}{ }^{0}=\{000,010,110,100\}, C_{3}{ }^{1}=\{001,011,111$, $101\}$ and the Hamming distances are 1.

Suppose that for $\mathrm{k}=\mathrm{c}$, the Hamming distances between consecutive elements in $\mathrm{C}_{\mathrm{c}}{ }^{0}$ and $\mathrm{C}_{\mathrm{c}}{ }^{1}$ are 1 .

We will show that the property holds for $\mathrm{k}=\mathrm{c}+1$. Let $\mathrm{C}_{\mathrm{c}+1}=\left\{0 \mathrm{C}_{\mathrm{c}}, 1 \mathrm{C}_{\mathrm{c}}{ }_{\mathrm{c}}\right\}$ be the Gray code of order $\mathrm{c}+1$ and let $\mathrm{x} 0$ and $\mathrm{y} 0$ be two consecutive elements in $\mathrm{C}^{0}{ }_{\mathrm{c}+1}$. If $\mathrm{x} 0$ and $\mathrm{y} 0$ are both in $0 \mathrm{C}_{\mathrm{c}}$ or $1 \mathrm{C}_{\mathrm{c}}$ then they are consecutive in $\mathrm{C}_{\mathrm{c}}{ }^{0}$ and the Hamming distance is 1 . If $0 \mathrm{x} 0$ is the last string finishing with 0 in $0 \mathrm{C}_{\mathrm{c}}$ and $1 \mathrm{y} 0$ the first string finishing with 0 in $1 \mathrm{C}_{\mathrm{c}}$ then, according to lemma 7, $\mathrm{x} 0$ is the last element in $\mathrm{C}_{\mathrm{c}}$ and $\mathrm{y} 0$ is the first element in $\mathrm{C}^{\prime}{ }_{\mathrm{c}}$ and $\mathrm{x}=\mathrm{y}$. Then $\mathrm{H}(\mathrm{x} 0, \mathrm{y} 0)=1$ for any two consecutive elements $\mathrm{x} 0, \mathrm{y} 0$ in $\mathrm{C}_{\mathrm{c}}{ }^{0}$. In the same way, the Hamming distance between two consecutive elements in $\mathrm{C}_{\mathrm{c}}{ }^{1}$ is 1 and the lemma is proved.

Using these two lemmas we can prove the following theorem:

Theorem 8: Any extended Fibonacci cube $\operatorname{EFC}_{k}(n)$, $\mathrm{k}>1, \mathrm{n}>\mathrm{k}+1$, is hamiltonian.

Proof: Let $\mathrm{EG}_{\mathrm{k}}(\mathrm{n})$ be the extended Fibonacci sequence, $\mathrm{EG}_{\mathrm{k}}(\mathrm{n})=\left\{\mathrm{v}_{1} \mathrm{C}_{\mathrm{k}}, \mathrm{v}_{2} \mathrm{C}_{\mathrm{k}}, \mathrm{v}_{3} \mathrm{C}_{\mathrm{k}}, \ldots, \mathrm{v}_{\mathrm{q}} \mathrm{C}{ }_{\mathrm{k}}\right\}, \mathrm{q}=\mathrm{f}_{\mathrm{n}-\mathrm{k}}$ with $\mathrm{C}_{\mathrm{k}}$ and $\mathrm{C}^{\prime}{ }_{\mathrm{k}}$ the Gray codes of order $\mathrm{k}$ and $\mathrm{v}_{\mathrm{i}}, 1 \leq \mathrm{i} \leq \mathrm{f}_{\mathrm{n}-\mathrm{k}}$ the Fibonacci strings with length $\mathrm{n}-\mathrm{k}-2$ and we denote $\mathrm{EG}_{\mathrm{k}}(\mathrm{n})=\left\{\mathrm{z}_{1}, \mathrm{z}_{2}, \ldots, \mathrm{z}_{\mathrm{pq}-1}, \mathrm{z}_{\mathrm{pq}}\right\}, \mathrm{pq}=2^{\mathrm{k}} \mathrm{f}_{\mathrm{n}-\mathrm{k}}$. We define the subsequences $\left.\operatorname{EG}_{\mathrm{k}}(\mathrm{n}) \stackrel{=}{=} \mathrm{z}_{1}^{0}, \mathrm{z}_{2}^{0}, \ldots, \mathrm{z}_{\mathrm{m}}{ }^{0}\right\}$ and $\mathrm{EG}_{\mathrm{k}}{ }^{1}(\mathrm{n})=\left\{\mathrm{z}_{1}{ }^{1}, \mathrm{z}_{2}{ }^{1}, \ldots, \mathrm{z}_{\mathrm{m}}{ }^{1}\right\}$ that contain the consecutive strings in $\mathrm{EG}_{\mathrm{k}}(\mathrm{n})$ that have the symbol 0 respectively 1 on their last position, $m=p q / 2$. From the definition of 
$\mathrm{EG}_{\mathrm{k}}(\mathrm{n})$ is easy to see that $\mathrm{EG}_{\mathrm{k}}^{0}(\mathrm{n})=\left\{\mathrm{v}_{1} \mathrm{C}_{\mathrm{k}}{ }^{0}, \mathrm{v}_{2} \mathrm{C}_{\mathrm{k}}{ }_{\mathrm{k}}^{0}\right.$, $\left.\mathrm{v}_{3} \mathrm{C}_{\mathrm{k}}{ }^{0}, \mathrm{v}_{4} \mathrm{C}_{\mathrm{k}}{ }_{\mathrm{k}}^{0}, \ldots, \mathrm{v}_{\mathrm{q}} \mathrm{C}^{\prime \prime}{ }_{\mathrm{k}}^{0}\right\}, \mathrm{EG}_{\mathrm{k}}{ }^{1}(\mathrm{n})=\left\{\mathrm{v}_{1} \mathrm{C}_{\mathrm{k}}{ }^{1}, \mathrm{v}_{2} \mathrm{C}^{\prime}{ }_{\mathrm{k}}{ }^{1}, \mathrm{v}_{3} \mathrm{C}_{\mathrm{k}}{ }^{1}\right.$, $\mathrm{v}_{4} \mathrm{C}_{\mathrm{k}}{ }^{1}, \ldots, \mathrm{v}_{\mathrm{q}} \mathrm{C}{ }^{\prime}{ }_{\mathrm{k}}^{1}$ \}.

Let $\mathrm{x} 0$ and $\mathrm{y} 0$ be two consecutive elements in $\mathrm{EG}_{\mathrm{k}}{ }^{0}(\mathrm{n})$. If $\mathrm{x} 0$ and $\mathrm{y} 0$ are consecutive elements in a subsequence $\mathrm{v}_{\mathrm{i}} \mathrm{C}_{\mathrm{k}}{ }^{0}$ or $\mathrm{v}_{\mathrm{i}} \mathrm{C}_{\mathrm{k}}{ }_{\mathrm{k}}^{0}$ then, according to lemma 8 , the Hamming distance between them is 1 (this can happen only if $\mathrm{k}>2$ ). If $\mathrm{x} 0$ is the last element in $\mathrm{a}_{\mathrm{i}} \mathrm{C}_{\mathrm{k}}{ }^{0}$ and $\mathrm{y} 0$ is the first element in $\mathrm{v}_{\mathrm{i}+1} \mathrm{C}_{\mathrm{k}}{ }^{0}$ then, using lemma 7, the Hamming distance between them is $\mathrm{H}(\mathrm{x} 0, \mathrm{y} 0)=\mathrm{H}\left(\mathrm{v}_{\mathrm{i}} \mathrm{w}_{\mathrm{p}}, \mathrm{v}_{\mathrm{i}+1} \mathrm{w}_{\mathrm{p}}\right)=\mathrm{H}\left(\mathrm{v}_{\mathrm{i}}, \mathrm{v}_{\mathrm{i}+1}\right)=1$. If $\mathrm{x} 0$ is the last element in $\mathrm{a}_{\mathrm{i}} \mathrm{C}_{\mathrm{k}}{ }_{\mathrm{k}}$ and $\mathrm{y} 0$ is the first element in $\mathrm{V}_{\mathrm{i}+1} \mathrm{C}_{\mathrm{k}}{ }^{0}$ then the Hamming distance between them is $\mathrm{H}(\mathrm{x} 0, \mathrm{y} 0)=\mathrm{H}\left(\mathrm{v}_{\mathrm{i}} \mathrm{w}_{1}, \mathrm{v}_{\mathrm{i}+1} \mathrm{w}_{1}\right)=\mathrm{H}\left(\mathrm{v}_{\mathrm{i}}, \mathrm{v}_{\mathrm{i}+1}\right)=1$. This means that the Hamming distance between two consecutive elements in $\mathrm{EG}_{\mathrm{k}}{ }^{0}(\mathrm{n})$ is 1 . In the same way, the Hamming distance between two consecutive elements in $\mathrm{EG}_{\mathrm{k}}{ }^{1}(\mathrm{n})$ is one. The first two elements in $\mathrm{EG}_{\mathrm{k}}(\mathrm{n})$ are the first two elements in $\mathrm{v}_{1} \mathrm{C}_{\mathrm{k}}$ and the last two elements in $\mathrm{EG}_{\mathrm{k}}(\mathrm{n})$ are the last two elements in $\mathrm{v}_{\mathrm{q}} \mathrm{C}{ }_{\mathrm{k}}$. According to lemma 7, $\mathrm{z}_{1}=\mathrm{z}_{1}{ }^{0}, \mathrm{z}_{2}=\mathrm{z}_{1}{ }^{1}$, $\mathrm{z}_{\mathrm{pq}-1}=\mathrm{z}_{\mathrm{m}}{ }^{0}, \mathrm{z}_{\mathrm{pq}}=\mathrm{z}_{\mathrm{m}}{ }^{1}$. We define the sequence $\left\{\mathrm{EG}_{\mathrm{k}}{ }^{0}(\mathrm{n})\right.$, $\left.\left(\mathrm{EG}_{\mathrm{k}}{ }^{1}(\mathrm{n})\right)^{\prime}\right\}=\left\{\mathrm{z}_{1}{ }^{0}, \mathrm{z}_{2}{ }^{0}, \ldots, \mathrm{z}_{\mathrm{m}}{ }^{0}, \mathrm{z}_{\mathrm{m}}{ }^{1}, \mathrm{z}_{\mathrm{m}-1}{ }^{1}, \ldots, \mathrm{z}_{1}{ }^{1}\right\}$ in which the Hamming distance between two consecutive elements is 1 and the Hamming distance between the first and the last element is 1 . This means the sequence defines a hamiltonian cycle in the extended Fibonacci cube $\mathrm{EFC}_{\mathrm{k}}(\mathrm{n})$.

In other words, a hamiltonian cycle in an extended Fibonacci cube can be defined from the extended Fibonacci sequence $\mathrm{EG}_{\mathrm{k}}(\mathrm{n})$ traversing the nodes with 0 on their last position from the first to the last and then the nodes with 1 on their last position from the last to the first as they appear in $\mathrm{EG}_{\mathrm{k}}(\mathrm{n})$.

As a consequence of theorem 8 , we can give the following corollary:

Corollary 9: Any ring of length $2^{\mathrm{k}} \cdot \mathrm{f}_{\mathrm{j}}, \mathrm{j}<\mathrm{n}-\mathrm{k}$, can be embedded with dilation and congestion one in an extended Fibonacci cube $\operatorname{EFCk}(n)$, where $f_{j}$ is the $j$-th Fibonacci number.

Proof: Using the recursive structure of the extended Fibonacci cube, an $\operatorname{EFC}_{\mathrm{k}}(\mathrm{n})$ has as subgraphs all extended Fibonacci cubes $\operatorname{EFC}_{k}(m), k+1<m<n$. All $\mathrm{EFC}_{\mathrm{k}}(\mathrm{m})$ are hamiltonian, then rings of length $2^{\mathrm{k}} \mathrm{f}_{\mathrm{m}-\mathrm{k}}$ can be embedded in $\mathrm{EFC}_{\mathrm{k}}(\mathrm{m})$ and it follows that rings of length $2^{\mathrm{k}} \mathrm{f}_{\mathrm{m}-\mathrm{k}}$ can be embedded in $\mathrm{EFC}_{\mathrm{k}}(\mathrm{n}), \mathrm{k}+1<\mathrm{m}<\mathrm{n}$.

For $\mathrm{EFC}_{2}(6)$ the extended Fibonacci sequence is $\mathrm{EG}_{2}(6)=\{0100,0101,0111,0110,0010,0011,0001$, $0000,1000,1001,1011,1010\}, \mathrm{EG}_{2}{ }^{0}(6)=\{0100,0110$, $0010,0000,1000,1010\}, \mathrm{EG}_{2}{ }^{1}(6)=\{0101,0111,0011$, $0001,1001,1011\}$ and a hamiltonian cycle in $\mathrm{EFC}_{2}(6)$ can be defined as $\left\{\mathrm{EG}_{2}{ }^{0}(6),\left(\mathrm{EG}_{2}{ }^{1}(6)\right)^{\prime}\right\}=\{0100,0110$, 0010, 0000, 1000, 1010, 1011, 1001, 0001, 0011, 0111, $0101\}$.

The hamiltonian cycle in $\mathrm{EFC}_{2}(6)$ is represented in Fig. 3, the dashed lines are the edges not in the hamiltonian cycle.

A two dimensional mesh can also be embedded in an extended Fibonacci cube. We use the construction presented for Fibonacci cubes ${ }^{[13]}$.

Theorem 9: A 2D mesh with $\mathrm{f}_{\mathrm{n}-\mathrm{k}}$ lines and $2^{\mathrm{k}}$ columns can be embedded in an extended Fibonacci cube $\mathrm{EFC}_{\mathrm{k}}(\mathrm{n})$ with dilation and congestion one.

Proof: We define the two dimensional mesh as it follows: we label the $i$-th line of the mesh with the $i$-th Fibonacci code in $\mathrm{G}_{\mathrm{n}-\mathrm{k}}=\left\{\mathrm{v}_{1}, \mathrm{v}_{2}, \ldots, \mathrm{v}_{\mathrm{q}}\right\}, \mathrm{q}=\mathrm{f}_{\mathrm{n}-\mathrm{k}}$ and the $\mathrm{j}$-th column with the $\mathrm{j}$-th binary string in $\mathrm{C}_{\mathrm{k}}=\left\{\mathrm{w}_{1}\right.$, $\left.\mathrm{w}_{2}, \ldots, \mathrm{w}_{\mathrm{p}}\right\}, \mathrm{p}=2^{\mathrm{k}}$. The label of the node in the line $\mathrm{i}$ and column $\mathrm{j}$ will be the concatenation of the line label with the column label. The defined mesh has $\mathrm{f}_{\mathrm{n}-\mathrm{k}}$ lines and $2^{\mathrm{k}}$ columns, each node of the mesh corresponding to the node with the same label in the extended Fibonacci cube $\mathrm{EFC}_{k}(n)$. If $\mathrm{v}_{\mathrm{i}} \mathrm{w}_{\mathrm{j}}$ is the label of a node in line $i$ and column $j$ of the mesh, then its neighbours are $\mathrm{v}_{\mathrm{i}-1} \mathrm{w}_{\mathrm{j}}, \quad \mathrm{v}_{\mathrm{i}+1} \mathrm{w}_{\mathrm{j}}, \quad \mathrm{v}_{\mathrm{i}} \mathrm{w}_{\mathrm{j}-1}, \mathrm{v}_{\mathrm{i}} \mathrm{w}_{\mathrm{j}+1}$. The Hamming distance between the node and its neighbours in the mesh is 1 so these nodes are neighbours in the extended Fibonacci cube $\mathrm{EFC}_{\mathrm{k}}(\mathrm{n})$ too, that means the congestion and the dilation of the embedding are one.

For the extended Fibonacci cube $\mathrm{EFC}_{2}(6)$, the two dimensional mesh with $2^{2}=4$ columns and $\mathrm{f}_{4}=3$ lines will be constructed in Fig. 4, the dashed lines are the edges not in the mesh.

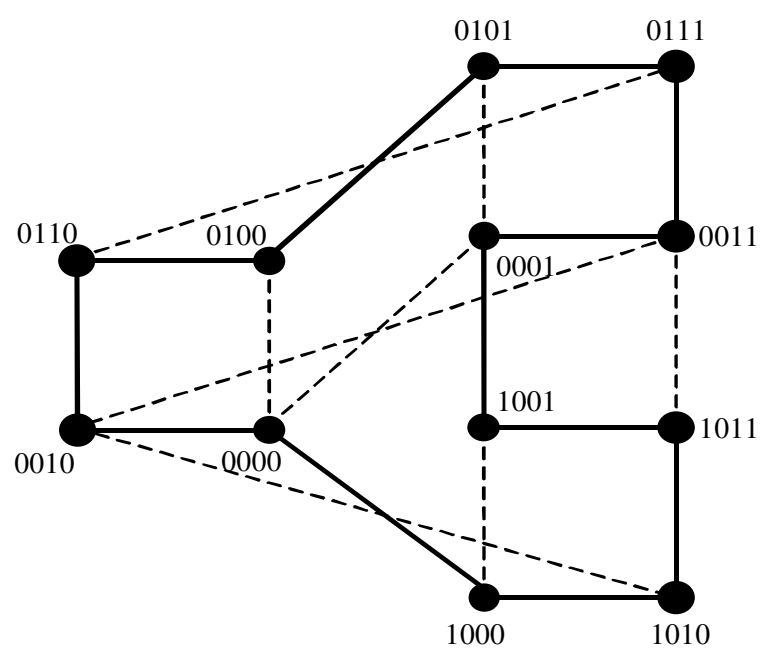

Fig. 3: Hamiltonian cycle in $\mathrm{EFC}_{2}(6)$ 

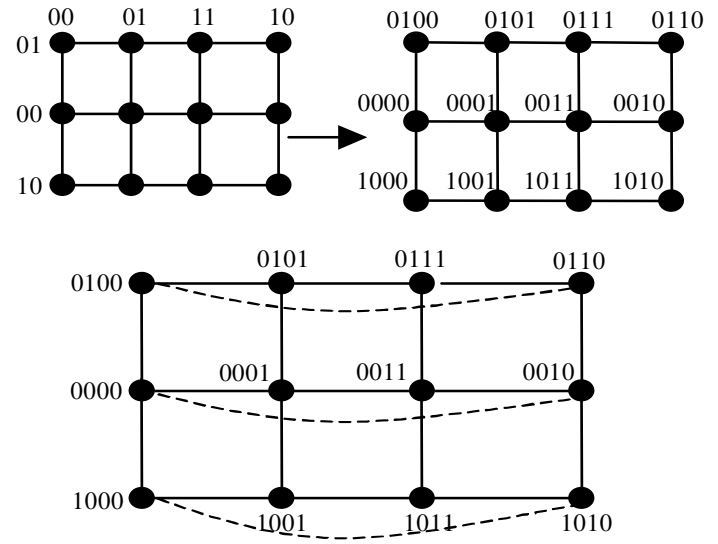

Fig. 4: 2D mesh embedding in $\mathrm{EFC}_{2}(6)$

\section{CONCLUSIONS}

The capacity of an interconnection network to emulate a basic topology as hamiltonian path or cycle and 2D mesh, hypercubes and trees, is of a great importance in the case that links in the network fail. In this case the network can keep functioning with a relatively small number of links. Other advantages are that a lot of algorithms are already developed for these basic topologies. The extended Fibonacci cube can efficiently emulate these basic topologies. Together with its recursive structure, small degree and diameter, various numbers of nodes, the embeddings presented in this research make the extended Fibonacci cube a topology to consider as interconnection topology.

\section{REFERENCES}

1. Akers, S. and B. Krishnamurthy, 1989. A group theoretic model for symmetric interconnection networks. IEEE Trans. Comput., 38: 555-566.
2. Cong, B., S.Q. Zheng and S. Sharma, 1993. On Simulations of linear arrays, rings and 2D meshes on Fibonacci cube networks. Proc. 7th Intl. Parallel Processing Symp.: 748-751.

3. Hsu, W.J. and M.J. Chung, 1993. Generalized Fibonacci cubes. Proc. Intl. Conf. Parallel Processing, 1: 299-302.

4. Hsu, W.J., 1991. Fibonacci cubes- properties of an asymmetric interconnection topology. Proc. Intl. Conf. on Parralel Processing, pp: 1249-1268.

5. Hsu, W.J., 1993. Fibonacci cubes-a new interconnection topology. IEEE Trans. On Parallel Distributed Syst., 4 (1): 3-12.

6. Karci, A., 2001. New Interconnection Networks: Fibonacci Cube and Extended Fibonacci Based Hierarchic Networks, Proc. $15^{\text {th }}$ Intl. Conf. On Information Networking, pp. 869-876.

7. Katseff, H., 1988. Incomplete hypercubes. IEEE Trans. Comput., 37 (5): 604-608.

8. Scarano, V., 1999. On the sizes of extended Fibonacci cubes. IEEE Trans. Parallel Distributed Syst., 10 (7): 764-766.

9. Stojmenovic, I., 1998. Optimal deadlock-free routing and broadcasting on Fibonacci cube networks. Utilitas Math., 53: 159-166.

10. Tanenbaum, A.S., 1981. Computer networks. Englewood Cliffs, Prentice Hall.

11. Wu, J., 1997. Extended Fibonacci cubes. IEEE Trans. on Parallel Distributed Syst., 8 (12): 12031210.

12. Zelina, I., 2005. Parallel Lagrange interpolation in extended Fibonacci cubes. Studia Univ. BabeşBolyai, L, 1: 105-110.

13. Zelina, I., 2006. On embedding Fibonacci meshes on Fibonacci cube networks. Carpathian J. Math., 22 (1-2): 173-178. 